\title{
LA MEMORIA, LA COEDUCACIÓN Y LA PAZ
}

\section{MEMORY, COEDUCATION AND PEACE}

\author{
Abilio VERGARA FIgUEROA* \\ Escuela Nacional de Antropología e Historia (ENAH)
}

Resumen: Uno de los factores fundamentales para comprender la problemática de la paz es el de la memoria. Un presupuesto de este artículo es que dicha memoria se realiza en el lenguaje, especialmente en el lenguaje articulado, que es el medio por el que se hace pública y se despliega, no sólo la expresión de un pasado, sino también las perspectivas que orientan nuestras argumentaciones para el presente y el futuro. Cuando hablo de lenguaje, me refiero al habla (en el sentido de Saussure) desplegada en una época, y en contextos biográficos y comunidades interpretativas (Thompson, 1993) de cada uno y de cada comunidad, teniendo en cuenta dos conceptos básicos: lo imaginario (el flujo entre memoria e imaginación) y la ideología, que están relacionados con la educación y las condiciones de vida, colectivas e individuales.

En este artículo se abordan los problemas asociados a las posibilidades de formulación de las políticas de paz en su nivel intermedio, es decir las que median entre las escalas macro y micro, con especial énfasis en las últimas, que es donde la memoria, la acción colectiva y la autoreflexividad pueden aportar significativamente.

Palabras clave: memoria, paz, educación, lenguaje, imaginario.

Авstract: One of the key factors to understand the matter of peace is by understanding how memory works. What I suggest in this article is that memory is carried out in the language, especially in the articulated language. Memory is made public and is deployed through language, it deploys not only the expression of the past but also the perspectives that guide our arguments to express the present and the future. When

*abiliovergara@yahoo.com.mx 
I refer to language, I consider the speech (in the sense of Saussure) deployed at a time, and in biographical contexts and interpretative communities (Thompson, 1993) of each one and each community, considering two basic concepts: the imaginary (flow between memory and imagination) and the ideology, which are related to the education and living conditions, collectively and individually.

In this article we address the issues associated with the possibilities of formulation of peace policies at an intermediate level, for instance, the ones that mediate between the macro and micro scale, with special emphasis on the last one, which is where memory, collective action and self-reflection can contribute significantly.

KEYwORDs: memory, peace, education, language, imagination.

La complejidad del problema de la paz repercute -si uno no sólo la reflexiona, sino la «habita»-, en lo personal, porque su problematización necesariamente lo implica a uno. Por esta razón, este escrito no entrega conclusiones, sino reflexiones y cuestionamientos, espero, eso sí, complejos y profundos. Adelanto que una de mis preocupaciones centrales es la violencia como antagonista de la paz, pero no sólo la que se da hacia abajo, es decir desde los centros de poder hacia la sociedad, sino la que se da abajo, entre pobres, entre vecinos, entre familiares, e inclusive la que nos infligimos a nosotros mismos.

Paz, palabra demasiado grande cuando se la confronta-asocia con la guerra, se vuelve pequeña, casi íntima, cuando se dice: «¡Déjame en paz!». Esta ubicación es importante -por la escala que designa y abarca-, y es el motivo de que incorpore menos lo macro-estructural ${ }^{1}$, circunscribiéndome más a lo que en la escala micro nos toca hacer, que es también la escala donde mejor podemos contribuir.

\footnotetext{
1 Porque también es lo que está más lejos de nuestro poder de influencia y atañe a los poderes institucionales donde no podemos incidir más fácilmente, mientras que en lo cotidiano, no sólo podemos actuar, sino que no podemos renunciar a hacerlo so pena de ser afectados nosotros mismos.
} 


\section{I.- La cultura de la paz y sus problemáticas}

Primera cuestión metodológica: conceptuar la paz situando al emisor y definiendo sus horizontes, quién habla, con qué intención.

«La única cosa que nos queda frente a esa ineludible derrota que se llama vida es intentar comprenderla» (Zygmunt Bauman).

Inicio señalando que sólo esforzándonos por saber, y hacer saber desde qué lugares, posicionamientos y horizontes hablamos, es decir, clarificando cuáles son nuestras preguntas o hipótesis y nuestros presupuestos - cuáles nuestras categorías, conceptos, nociones y explicitando nuestros deseos e intereses-, podremos reflexionar y debatir con cierta claridad y provecho y, en la medida de lo posible, buscar perspectivas conjuntas o discrepar gradual o radicalmente.

Algunas de estas interrogaciones que pueden servir de marco podrían ser: ¿Qué es la paz, y cuál es su relación con las violencias? ¿Es la paz factible? ¿Qué papel juega la memoria? ¿Qué horizontes o escalas sociales y políticos debemos considerar para reflexionar y debatir adecuadamente? ¿Es la paz más importante que la justicia y la verdad? (¿Es pertinente esta pregunta?) ¿Qué papel juega el perdón frente a la justicia? ¿Sentir culpa o arrepentirse es condición para ser perdonado? ¿Se puede perdonar sin sentir liberación, por ese acto (o antes) del dolor y del odio que la memoria actualiza? Si hay beneficiarios con el perdón, ¿qué le pasa a la víctima y qué al victimario? ¿Qué papel juega el olvido en la cultura de paz? ¿Es más importante la verdad o la felicidad? ¿Y el castigo? ¿Buscar en la naturaleza del hombre o buscar en la naturaleza de la sociedad? ¿Cómo afrontar su conflictiva interrelación? Y volver, y volver a repetir si son pertinentes estas preguntas, producir otras, alternativas o que maticen, dudar...

De lo anterior deriva la necesidad de clarificar el lenguaje y las perspectivas que orientan nuestras argumentaciones. De lo que se trata, no son sólo de palabras, sino de sintagmas, es decir del habla (en el sentido de Saussure) desplegada en una época, y en contextos biográficos y comunidades interpretativas (Thompson, 1993) de cada uno. Dos factores a considerar en esta definición de nociones, categorías y conceptos son lo imaginario (el flujo entre memoria e imaginación) y la ideología, que están relacionados con la Educación y las condiciones de vida, colectivas e individuales. 
En el discurso de recepción del Premio Príncipe de Asturias, el pensador y sociólogo polaco Zygmunt Bauman dice que El Quijote, nos ayuda a "rasgar el telón, comprender la vida», y agrega que, «nosotros, [los] humanos, preferiríamos habitar un mundo ordenado, limpio y transparente donde el bien y el mal, la belleza y la fealdad, la verdad y la mentira estén nítidamente separados entre sí y donde jamás se entremezclen, para poder estar seguros de cómo son las cosas, hacia dónde ir y cómo proceder. Soñamos con un mundo donde las valoraciones puedan hacerse y las decisiones puedan tomarse sin la ardua tarea de intentar comprender. De este sueño nuestro nacen las ideologías, esos densos velos que hacen que miremos sin llegar a ver. Es a esta inclinación incapacitadora nuestra a la que Étienne de la Boétie denominó "servidumbre voluntaria” (Bauman, 2017²), y denuncia su carácter tramposo. Habría que agregar que la ideología sujeta a la memoria, la fuerza a seleccionar dentro de su marco, y bajo sus dispositivos.

Bauman continúa, y dice que Cervantes, al denunciar esa «servidumbre voluntaria», abrió el camino de salida que nos aleja de esa servidumbre "para que pudiésemos seguirlo, presentando el mundo en toda su desnuda, incómoda, pero liberadora realidad: la realidad de una multitud de significados y una irremediable escasez de verdades absolutas. Es en dicho mundo, en un mundo donde la única certeza es la certeza de la incertidumbre, en el que estamos destinados a intentar, una y otra vez y siempre de forma inconclusa, comprendernos a nosotros mismos y comprender a los demás, destinados a comunicar y de ese modo, a vivir el uno con y para el otro" (Bauman, 2017). En este proceso, es fundamental prestar atención al lenguaje que es donde reside la memoria.

\section{Presupuestos del lenguaje de este texto}

«Vivir el uno con y para el otro» es, precisamente, el meollo de esta reflexión, e implica considerar la ecología de la palabra y la ecología de la escucha, como camino al otro y la cultura de la paz. Yo intentaré señalar algunos puntos donde se ubican mis palabras, ustedes lectores piensen en qué condiciones interpretan o comprenden. Ese es también el reto.

2 El Mundo, 09/01/2017. 
En relación a la interacción entre mis palabras y vuestro entendimiento, debo seńalar que cada palabra o frase, colocada en determinado sintagma habita una específica ecología, que le otorga un significado preciso; sin embargo, determinado intérprete lo puede hacer escapar hacia otro sintagma en esa otra ecología, es decir el nuevo contexto interior que ahora lo cobija (el de cada lector), desde donde puede surgir tanto la comprensión compartida, como el malentendido, la sobre-interpretación o el desfiguro que puede llevar al antagonismo y la confrontación, a veces innecesaria, inclusive entre «buenas personas». Por ejemplo: la paz, que yo considero una tarea siempre inconclusa, puede imaginarse como la utopía, es decir, un objetivo inalcanzable. Una sensibilidad, un trauma, un temor o recelo, un estereotipo o un dogmatismo pueden constituirse en dispositivos que arrancan a la palabra del sentido que le otorgaba su formulación inicial, para arraigarla en otra formulación: la del interpretante, la del lector, la del oyente, intentando descalificarla desde esa otra interpretación/perspectiva. Por ello, aprender a aclarar oportuna y adecuadamente los malentendidos (y mostrar sus dispositivos), puede ser una de las tareas de la coeducación.

Otro asunto que tiene que ver con el lenguaje de este texto, es la manera en que pienso en la condición actual de la certeza. En la vida diaria, y en amplios sectores sociales, uno encuentra personas que están muy convencidas de sus ideas, pensamientos y creencias: creen lo que piensan de manera absoluta (claro, hay también quienes, y son muchos, habitan la duda como incertidumbre ${ }^{4}$ constante y angustiosa) que lo que piensan es la verdad única y, por ende, inobjetable. Podría decir que envidio a esas personas, que yo también quisiera creer como ellas, creer con indudable seguridad, con lo que, quizá, ganaría mayor confianza en mí mismo y en quienes habitan conmigo este mundo o elaboraría con mayor determinación inclusive mis enemistades. Sin embargo, también debo confesar que me da miedo creer en absolutos, porque de esa forma sepultaría mis dudas desde las cuales emergen mis preguntas. Si ya no dudo, la cosa se vuelve fácil, pero simple, y toda simpleza es epidérmica y no ayuda a pensar. Diría yo, entonces, dudo, luego existo.

Lo anterior proviene de que considero que el ser humano es posibilidad, potencia y limitación, proceso sin fin; criatura que se hace con desiguales recursos,

\footnotetext{
3 También puede ser secuestrada, interesadamente, por la inquina ideológica, por la animadversión personal, por la búsqueda interesada, etc.

4 Sobre ello Bauman, en varias de sus obras, lo figura a través de la imagen de lo líquido.
} 
que aspira y asciende, pero también declina y se degrada (y puede rehabilitarse, resiliencia). Es éste el punto de mi partida, tanto de mi pesimismo como de mi optimismo.

\section{Contextos contemporáneos: la escala macro-estructural}

Es la escala preferida de quienes piensan que la (cultura de) paz no es posible.

Un elemento importante para hablar de la paz son los contextos o niveles, de diversa escala y poder. En este sentido, me gustaría sólo enumerar ocho fenómenos de carácter político y sociocultural que articulan escalas globales, nacionales y locales, que afectan las interacciones cotidianas entre las personas.

1.- El sistema capitalista globalizado, según los escépticos, «la madre de todas las serpientes", productor de guerras y de un sentido materialista-consumista de la vida, donde se privilegian «los recursos» frente a los humanos y a la naturaleza.

2.- La globalización, lo complejo contemporáneo, las tecnologías que ensanchan el espectro de posibilidades que se presentan a nuestra acción (Melucci, 2001: $120)$, donde «es imposible no elegir. Hasta la no elección es un modo de elegir» (2001: 121).

3.- Hoy, el poder político emana más del capital financiero y, en consecuencia, está a su servicio.

4.- Banalización del lenguaje y del pensamiento. Encumbramiento de la sin razón, la estupidez y la irresponsabilidad en la cima del poder (como expresión de las deficientes condiciones educativas de las mayorías), como lo muestran los triunfos de Trump y Bolsonaro: «un fascismo en busca de un Estado y no un Estado que moldea fascistamente a la sociedad».

5.- El binomio corrupción e impunidad se imponen, pero también se resisten.

6.- Asimismo, asistimos a la formulación de la cultura de eventos y «series» como espectacularización de la vida y de las noticias. 
7.- También vemos como el «estado de excepción» es convertido en norma, que se manifiesta en la proliferación de puestos de control: comisarías, cámaras de vigilancia, controles de inmigrantes... Su finalidad: identificar, separar, someter.

8.- La guerra, no sólo las que están realizándose (Siria, Israel y Palestina, por ejemplo), sino también las potenciales, las que se amenaza (Trump).

Hasta aquí lo estructural básico, pasamos a continuación a reflexionar sobre algunas categorías necesarias.

\section{Conflicto, diferencia y violencia}

Para aproximarnos a una concepción de lo que es la paz, es necesario reflexionar acerca de los matices entre conflicto, violencia y guerra (entre otros), y también entre identidad, diferencia y alteridad. Una ruta de reflexión muy productiva podría iniciarse si ubicamos a la violencia como intensificación del conflicto, y a la paz como su gestión ${ }^{5}$ y horizonte. Así, podríamos ver que no todo conflicto tiene que ser violento, aunque toda violencia encarna conflictividad.

El sociólogo alemán Georg Simmel indica que la socialización tiene dos componentes: la armonía y el conflicto, y no hay forma de eliminar uno de ellos. En este sentido, el análisis sobre las condiciones de la paz, requiere poner en la reflexión y el debate los distintos factores de conflictividad, como pobreza, dominación, explotación, desigualdad, discriminación, desprecio, racismo, clasismo, sexismo, machismo, corrupción-impunidad, entre otros. Estos son, para los escépticos, los que impiden la paz. Lo son, pero no en definitiva, por lo menos en cierta escala.

En esta misma dirección, es importante recordar la articulación que buscaba establecer Walter Benjamin entre violencia y orden (Ley), al decir que «toda violencia es, como medio, poder que funda o conserva el derecho. Si no

\footnotetext{
5 Al hablar de gestión, debe señalarse quiénes, en qué contextos o situaciones, con qué poderes, frente a quiénes, etc.

6 La armonía es también un componente del conflicto, puesto que, a diferente escala, diferentes grupos pueden cooperar entre sí, para enfrentar a otros.
} 
aspira a ninguno de estos dos atributos, renuncia por sí misma a toda validez. Pero de ello se desprende que toda violencia como medio, incluso en el caso más favorable, se halla sometida a la problematicidad del derecho en general» (Benjamin, 2010: 164-165). Es decir, que la violencia adquiere legitimidad histórica, sólo cuando en su perspectiva está la paz, que promueve o propicia la ley, que es (o debe ser) para todos ${ }^{7}$.

\section{¿Qué hacer con la diferencia y la alteridad?}

El antropólogo francés Claude Lévi-Strauss, en su libro Tristes trópicos, detecta que a lo largo de la historia la humanidad empleó dos estrategias para enfrentar la otredad. La primera consistía en expulsar («vomitarlos») a los que se consideraban extraños al grupo impidiendo «el contacto físico, el diálogo, el intercambio social y todas las variedades de commercium, comensalidad o connubium. Hoy, las variantes extremas de la estrategia "émica" son, como siempre, el encarcelamiento, la deportación y el asesinato. Las formas superiores y "refinadas" (modernizadas) de la estrategia "emica" son la separación espacial, los guetos urbanos, el acceso selectivo a espacios y la prohibición selectiva a ocuparlos» (Bauman, 2006: 109). Los condominios cerrados en las urbes (Caldeira, 2007), así como la "ciudad prohibida" (Davis, 2003), testifican esta opción.

La segunda estrategia consiste en la denominada «desalienación» de sustancias extrańas: «ingerir», "devorar» cuerpos y espíritus «idénticos», ya no diferenciables, al cuerpo que los ingirió. Esta estrategia revistió también un amplio espectro de formas: desde el canibalismo hasta la asimilación forzosa -cruzadas culturales, guerras de exterminio declaradas contra las costumbres, calendarios, dialectos y otros «prejuicios» $\mathrm{y}$ «supersticiones» locales ${ }^{8}$. «La primera estrategia tendía al exilio o la aniquilación de los otros; la segunda, a la suspensión o la aniquilación de su otredad» (Bauman, 2006: 109). La primera elimina sujetos, la segunda, sus cualidades.

\footnotetext{
7 Aquí podría objetarse (y de hecho lo hacen con enjundia quienes piensan que la paz es imposible) que la ley protege siempre el interés de los más poderosos, especialmente en la economía; sin embargo, será necesario estudiar la confrontación y los argumentos de su promulgación, para tener un cuadro más completo.

8 Los intentos de los Estados-nación por «integrar» a las poblaciones indígenas, como sucedió en México y Perú, fue parte de esta estrategia.
} 
Bauman propone una tercera estrategia: la producción de los no-lugares, donde la indiferencia hacia el otro, se supone, amaina el encono y la lucha. Por mi parte, yo propongo, su opuesto: umbrales, en el sentido de Stavros Stavrides (2016) y la construcción de horizontes compartibles, en el sentido de Gadamer.

\section{Las emociones, la violencia y la paz}

Arjum Appadurai advierte que la violencia en los años noventa del siglo XX se «presenta característicamente acompañada de un exceso de ira, de un plus de odio que produce formas nunca vistas de degradación y vejación en el cuerpo y en el propio ser de las víctimas» (Appadurai, 2007: 24). Constatándose que ocurre inclusive entre amigos, vecinos y familiares; agrega que es posible que este plus de violencia estuviera relacionado con «las deformaciones que la globalización ha introducido en el "narcisismo de las diferencias menores"» (Appadurai, 2007: 24-25). Habría que agregar como posible explicación de esta compleja problemática, el declive de las instituciones (Dubet, 2006) y, también habría que cuidar bien por dónde se busca la causa, su escala, su implicación con la facturación de la realidad y del ser. Hoy, la baja emocionalidad del criminal parece ir paralela al creciente sufrimiento de la víctima, y una acentuación de la indiferencia de la opinión pública.

Otro aspecto a considerar en la reflexión sobre la memoria y su relación con la cultura de la paz es la referida a la emocionalidad del sujeto en relación a cómo se conforma el Yo. A este respecto, Cornelius Castoriadis señala que,

El resultado del proceso de maduración/socialización consiste en la formación del individuo social que es, en sí mismo, un objeto extraño y extranjero desde el punto de vista del núcleo de la mónada de la psique (...) Por lo tanto, se convierte simultáneamente en el soporte de la transferencia del amor de sí mismo y del objeto de odio de las instancias psíquicas no reales, odio que alcanza... a todo lo que es exterior al núcleo psíquico. El Yo real no puede evitar ser objeto de la ambivalencia de los afectos. Habitualmente, el amor de este Yo se impone sobre el odio del cual es objeto, de una manera que alcanza para asegurar la supervivencia del sujeto en la realidad. Pero el odio del Yo sigue viviendo silenciosamente en las profundidades (Castoriadis, 2002: 186). 
Esta ambivalencia, puede repercutir en la calidad de la autoestima. Aceptarse es, de alguna manera, adaptarse al Otro lacaniano. El Yo real es objeto del núcleo psíquico en cuanto es evaluado, jerarquizado, identificado por dicho núcleo: de la correspondencia, de la armonía entre ambos o del grado de su diferencia o antagonismo dependerá en mucho la salud mental de las personas. La persona es, creo, el resultado de dicha tensa relación. Muchas veces, se han asociado crímenes con autoestimas deterioradas.

En este punto, cabrían algunas preguntas. ¿Hay momentos en que ese núcleo psíquico y el sí mismo se fusionan? (Quizá a esto llamemos felicidad) ¿Se mimetizan enmascarándosenos? ¿Qué pasa cuando el ridículo te abruma y odias al otro por propiciarlo? ¿Qué pasa cuando la indignación o la ira hacen que emerja un acto que te reivindique? El amor y el odio juegan en el mismo "territorio» aunque a diferentes niveles; estos niveles son móviles, sus fronteras se endurecen, pero también se relajan. ¿Es que los fundamentalistas deben sacrificar más? ¿Qué hacen con la energía que no descargan en el umbral entre sí mismo y el otro? ¿Es que los pandilleros, de quienes se dice tienen una baja autoestima, sicarios y terroristas, realizan ese odio del otro de manera desimbolizada y, por ende, menos culposa, al aminorar el odio a sí mismo a través de su victoria física? ¿Y por qué el cinismo en los relatos de muchos de ellos?

\section{Perdón y culpa versus justicia y reparación: trabajar sus emocionalidades}

Un asunto espinoso de los procesos de pacificación es la relación entre justicia y perdón, cuando se los asocia a castigo, memoria y verdad. En este sentido, para procesar el perdón, Paul Ricœur, recomienda desligar al sujeto del acto. Esto nos confronta con la necesidad de introducir una epistemología del sujeto: salir de la cosificación que la victimización y la injusticia trabajan, para entender al sujeto humano como incompleto y resiliente. El sujeto no es un acto, no es un error definitivo, no es un delito (aunque hay matices, que es indispensable, detectar). Véanse los casos de los Maras convertidos (El País, 02/02/19: 8-9) y el de Pilar Baeza, precandidata de Podemos, que luego de cumplir prisión por asesinato reclamaba reinserción (El País, 10/03/19: 21). Ricœur, plantea que la relación entre culpa y perdón es desproporcionada. 
¿Será? Se puede debatir y comprender esto, también observando, en cada caso9 las circunstancias, las posiciones que definen responsabilidades ${ }^{10}$, pensando el conflicto y la violencia como procesos que anidan en la memoria y pueden estar sujetas a olvido, determinado el poder de los implicados, entre otros factores.

Quizá también debamos pensar por qué, generalmente, oponemos el perdón (que atiende la culpa) a la justicia (que atiende la ley), sin analizar lo que han pasado y están pasando hoy los implicados. El daño es irreversible, el agresor puede rehacerse, pero también la víctima (o sus deudos): ¿qué hacer, cómo? Quizá aquí es más indispensable pensar en escalas y niveles.

Pensar, por ejemplo, que el lugar de la culpa es la memoria, la que es trabajada por ésta y por la imaginación que la "completa», intensifica o expande, y le da horizonte o cierra el hecho, ya concluido, aunque sigua presente, acechando desde «muy adentro». Quizá el lugar del perdón sea el futuro que se habita desde el instante en que se otorga. El beneficiario mayor, quizá sea quien fue víctima, y no necesariamente el victimario. ¿El sujeto criminal es el mismo hoy? ¿Y la víctima, también? ¿Se debe trabajar para que la culpa siga o para que decaiga?

\section{II.- Coeducación y paz: la dialogía necesaria}

Una primera reflexión que se me plantea cuando pienso en la relación entre la cultura de la paz, la coeducación y los múltiples factores que las condicionan, es en cómo se constituye lo humano. En este punto me parece que tres aspectos tienen una relevancia sustantiva: la actividad expresiva, simbólica y la racional (aquí entra lo utilitario, funcional, pragmático), como campos diferenciados (con frecuencia, antagonistas) y complementarios. Los tres tienen que ver -cada uno a su maneracon la producción de sentido del mundo, es decir, con el proceso cognoscitivo, de simbolización y con lo estético; éste, no sólo entendido como producción de belleza, sino también con todo el campo de lo lúdico y sus múltiples derivaciones, como el juego, el humor, lo informal creativo, etc. Una segunda reflexión tiene que ver con la necesidad de observar los cronotopos o espacios y tiempos en los que se desarrolla este proceso de humanización del ser, y me detengo en los

9 Véase el concepto de deíctico en Vergara (2018).

10 Véase Claus Roxin (2000), sobre la «responsabilidad mediata». 
espacios del ritual, de lo cotidiano, de la escuela, del espacio público y privado, etc., donde la memoria y la imaginación constituyen lo imaginario.

Veamos los asuntos previos relativos al simbolo y a la lengua, configuradores de lo humano.

\section{La coeducación y el papel del Símbolo}

Un primer punto a considerar en la conceptuación del símbolo es el que propone Gilbert Durand cuando establece la relación entre el inconsciente y la conciencia. El inconsciente es, dice, un «lugar, separado de la consciencia, en conflicto con ella y al que ésta no podía llegar directamente, que determina el comportamiento y el pensamiento humanos» (Gutiérrez, 2012: 72). La frontera es la censura, la que sólo puede evitarse por la acción simbólica: «El proceso de simbolización tendría, por lo tanto, su primer referente en el conflicto que surge entre las exigencias pulsionales (ello) y las exigencias morales que se autoimpone el individuo (superyó), al interiorizar los tabúes familiares, sociales y/o culturales relacionados con la lívido» (idem: 73). Éstas pueden aparecer como imágenes, actitudes o como discursos.

En el análisis de la naturaleza del simbolo, es importante distinguir palabra de imagen, porque aquella es un signo arbitrario y la imagen, no, porque ésta porta «en sí misma» el sentido. Siguiendo esta lógica, se puede decir que el carácter motivado del símbolo se aproxima en su «estructura» a la imagen, aún cuando puede también estar conformado por la palabra, objetos, gestos, etc. Por otro lado, el símbolo, al ser producto tanto de la naturaleza biológica y psíquica del individuo como del entorno cósmico, social, histórico y cultural, en el que éste se desarrolla, puede permitir acceder de forma oblicua (sin ser «detectado» por la censura) al inconsciente, porque su naturaleza imaginal le posibilita eludir a la censura, que proviene del súper yo y de las presiones sociales (donde habita el yo). Si esto ocurre con nosotros, con el yo, lo mismo puede ocurrir con el otro. En este proceso, es indispensable pensar la memoria desde la coeducación que considera la diferencia como un aporte, más que un obstáculo. La coeducación debe promover un doble viaje: el que se realiza hacia el otro, es, al mismo tiempo, un viaje interior: nos cambia. 
En este sentido, otro asunto que me interesa resaltar, como eje de mi exposición, es que la coeducación debería reflexionar sobre la necesidad de generar condiciones para desarrollar la capacidad de escucha que debería guiar la interlocución entre personas y grupos. Esta tarea buscaría, en lo posible, debilitar el poder de los convencidos, de aquellos que no dudan, de aquellos que buscan imponer, más que convencer. Argumentar es practicar la democracia.

Así, la tarea fundamental de la coeducación es la construcción permanente y progresiva de un orden democrático, es decir, el escenario donde los problemas se elaboren a través de la actividad reflexiva y la negociación, y en esto, la palabra, el lenguaje, es el mediador central. La dialogía y la dialéctica promueven la elaboración argumentada, a través de prácticas sociales y de negociaciones en distintos niveles y campos, como la vida cotidiana, el mundo laboral, el del tiempo libre y del entretenimiento, el de la calle, el de las actividades «culturales», el de la resistencia, la lucha y la política.

La forma en que hemos enfocado al símbolo, condiciona nuestra actividad hacia la memoria en la coeducación, la que debe ser orientada por ciertos fines ${ }^{11}$. Para perfilar objetivos y metas, considero indispensable reflexionar acerca de lo que considero lo Humano ${ }^{12}$, y lo ubico en trascender lo utilitario, lo funcional. Hay que dedicarle un tiempo a actividades expresivas, connotando o decorando al hábito y a lo que "sirve», postergando o matizando lo necesario: asignarle tiempo a una canción, a un colibrí, a las hojas de un árbol, a un libro, al rocío, a las nubes, cultivar estos tiempos, estas relaciones; y la educación actual no está capacitada para proveer esos escenarios. Por otro lado, también hay gente que vive en condiciones sub-humanas, y no necesariamente por la pobreza y las múltiples carencias, sino por la insignificancia que impone el consumismo y el mercado, así como las tecnologías, que condicionan la epidérmica vinculación con lo trascendente. Cornelius Castoriadis había detectado esta condición cuando dice:

11 De esta manera, la memoria ya no está anclada en el pasado, sino constituye un factor de la construcción de proyectos, una forma de apropiación recreativa del futuro.

12 No como un antagonismo contra la naturaleza, sino más bien como una dialogía con ella, como un estar sensible, estético-ético, de un hacer no utilitario, sino poético, amoroso. 
El imaginario de nuestra época es el imaginario de la expansión ilimitada, es la acumulación de baratijas: una tele en cada habitación, un microordenador en cada cuarto... eso es lo que hay que destruir. El sistema se apoya en este imaginario que está ahí y que funciona $(2002: 33)^{13}$.

Ahora, ya no vemos una computadora en cada habitación, sino en cada cuerpo, portátil, adherido a él, cuyo olvido causa ansiedad cuasi ontológica.

\section{Coeducación: definición}

Una cierta historia restringida de coeducación remite a la confrontación histórica entre dos modelos educativos: la escuela de roles separados por sexo, y la escuela mixta, ambos con connotaciones físicas y curriculares. En el llamado modelo de roles separados, niños y niñas tienen sus propias escuelas; está basado en el imaginario que atribuye roles sociales diferentes para cada género, donde los hombres se encargan de lo público y las mujeres de lo doméstico, repercutiendo en la desigualdad de oportunidades. Es más, en ciertas condiciones de clase, la mujer considerará a la casa como el lugar donde muestra su honorabilidad ${ }^{14}$.

En la actualidad, la escuela mixta, ya es mayoritaria en los sistemas educativos de los diferentes países. Ella surge de la idea de la igualdad entre todas las personas, por lo que es necesario y justo impartir la educación correspondiente a esta condición.

13 Castoriadis señala que la insignificancia «no es simplemente un estado que se ha instalado en el mundo contemporáneo, sino como una especie de desierto que se extiende» (2002: 37). En otro momento, Castoriadis señala que «la sociedad moderna ha convertido a los ciudadanos en consumidores» (2002: 39). Quizá sea importante también señalar que no hay una fuerza "maligna» que dirige, "que no hay conspiración, pero todo conspira en el sentido de que todo respira a la vez, todo respira en la misma dirección» (2002: 39-40). Véase García Canclini (1995), Consumidores y ciudadanos.

14 Jane Darke, lo señala al decir que «Mujeres respetables de la clase trabajadora querían visibilidad y reconocimiento de su destreza en la realización de su obra más primorosa, junto con una intimidad para los "quehaceres domésticos", incluida la tarea continuada de socialización de los hijos e hijas» (1998: 102). Ver también la tradición Helme (Vergara, 2010), donde el territorio (representado por las autoridades locales, quienes encarnan lo públicomasculino) supervigila la casa (representada por las mujeres) en cuanto a su orden e higiene, considerados signos de la decencia de la mujer-madre-esposa. 
Frente a estos modelos que se ubican en contextos sociales, culturales, políticos, históricamente definidos, se viene propugnando la llamada «escuela coeducativa", que no se basa en la idea de la igualdad entre los hombres y mujeres, sino en su diferencia, la que se entiende también como diversidad cultural. Por mi parte yo plantearía el interrogante de que esto ¿podría contribuir a la persistencia en lo cultural e históricamente construido, o, por el contrario, hay que asumir estos aspectos como algo a cambiar, o a mantener de otra forma? Uno de los retos de la coeducación radica en reconocer esta disyuntiva y trabajar para producir nuevos contenidos frente a dicha distinción. En este sentido, me surgen otras preguntas: ¿Cuáles diferencias se considerarán para hacer qué con ellas? ¿Una escuela transicional donde se construyan escenarios para que la diferencia no se convierta en desigualdad? Hay que considerar que la escuela reescribe sobre lo que la socialización temprana hizo al interior de la familia y la comunidad.

Desde esta perspectiva, lo que se propicia es:

- Convivir con respeto, buscando el equilibrio entre la libertad de uno y del otro.

- Evitar agresiones, sin distinción de motivos, así sean correctivos, en ningún medio o forma: insultos, sobrenombres, golpes, postergaciones discriminatorias. prójimo.

- Ayudar a pensar en el otro como uno, construyendo el semejante o

Una indicación necesaria se refiere a considerar también las condiciones peculiares de cada centro educativo, sus contextos y actores, las diferencias locales y micro-relacionales, la sedimentación cultural y social que lo cotidiano produce, para lo que será útil contrastar el modelo con las experiencias concretas, promoviendo el estudio de sus progresos y obstáculos.

Es necesario proponerse ciertas metas que ayuden a perfilar, con cierta claridad, los horizontes:

- Se debe trabajar en la capacitación y sensibilización de los maestros y maestras, promoviendo escenarios para las relaciones democráticas. 
- Abordar las condiciones emocionales de las relaciones sociales, con la finalidad de propiciar su elaboración emosignificativa. Esto incluye, por supuesto, la educación de la sexualidad.

- Otorgar relevancia a la tarea coeducativa, a fin de que los participantes sientan que su labor contribuye al bienestar individual y comunitario.

Hay que pensar, reitero, que la producción y reconocimiento de la diferencia y de lo diferente es relacional, y debe afrontarse partiendo de la propia subjetividad, promoviendo actuar entre, más que sobre, considerando las escalas, niveles y sectores, pues la diferenciación no sólo afecta a las relaciones intergenéricas, sino también las intragenéricas. A este respecto, Luisa Muraro señala que para ella una forma de ser feminista, es «continuar la búsqueda personal y cultivar la diferencia entre mujeres, incluso con los conflictos consiguientes» (2010: 104, cursivas mías).

\section{La individuación o ¿qué hacer con el yo y el nosotros?}

En la dirección planteada con relación a la procesualidad de la construcción del ser humano, un problema sustancial es qué hacer con el yo, con el ego. Esta tarea es hoy diferente y más compleja de las que afrontaron en las sociedades tradicionales y, aún, en las modernas. Hoy, en estos tiempos de modernidad líquida (Bauman), la tarea es multifocal y situacional, sin que elimine las responsabilidades del Estado, la escuela, la sociedad, la comunidad y la familia. El sociólogo italiano Alberto Melucci, lo formula así:

La relación con el otro se convierte de este modo en la posibilidad de elegir y de reconocer la diferencia. Una relación existe si y cuando lo que me distingue a mí del otro es aceptado y se convierte en la base de la comunicación. Así pues, el significado de la comunicación depende de lo que es común con el fin de descubrir y afirmar la alteridad. Podemos elegir comunicarnos, pero la posibilidad de elección introduce contingencia y riesgo en nuestras relaciones y las convierte en un campo de compromiso y desafío emocional" (2001: 126-127, cursivas mías). 
Con lo que, agrega Melucci, hay una necesidad de mayor autoconciencia y responsabilidad, «de un contacto más estrecho con nuestra experiencia interior».

Lo anterior nos remite a una relación más compleja con la memoria, y en general con lo aprendido en la escuela ya que introduce la caducidad de las utilidades adquiridas y exige una actualización constante que repercute en las capas de memoria que la diacronía sedimenta. Este es un problema no sólo educativo, sino existencial que la educación deberá afrontar con prontitud.

En la formulación de esta «experiencia interior», el género es fundamental, así, entre las prácticas y valorizaciones relacionadas con la intersubjetividad, Melucci plantea que la valorización del amor en la relación de pareja «ha favorecido, de alguna manera, la superación de ciertas disparidades», a pesar de que se mantiene la idea "de que la mujer debe expresarse a través del compañero (y finalmente a través de los hijos)» (Melucci, 2001: 132). No obstante, constata que «hoy, la necesidad que parece emerger de manera más clara es la superación de esta relación de fusión, la búsqueda de la identidad personal mediante la diferencia. En este cuadro la maternidad se transforma cada vez más de un destino a una posibilidad de elección» (Melucci, 2002: 132, cursivas mías).

Así también, la frontera entre lo privado y lo público -que era equiparable a femenino-masculino- se difumina, se hace porosa: lo personal se vuelve politico. «El movimiento de las mujeres sostiene otra libertad: no ya la libertad por la necesidad, sino la libertad de la necesidad, no la lucha por la igualdad, sino por la diferencia, no ya la libertad de hacer, sino la libertad de ser. El salto, la discontinuidad, parecen en verdad enormes con la tradición del marxismo y del movimiento obrero. "Lo personal es político" no es sólo una paradoja para considerar con atención, sino un desafío que deja marca en quien lo recoge, es una apelación capaz de movilizar energías colectivas para el cambio» (Melucci, 2002: 133-134). 
Lo anterior, es decir, lo referido a la responsabilidad individual y su impacto en el sistema, también se constata en los problemas ecológicos, y en todas las relaciones e interacciones sociales.

\section{La dialogía como marco para la coeducación}

El crítico literario y pensador ruso Mijaíl Bajtin, es quien ha desarrollado con mayor profundidad el concepto de dialogía, que es en última instancia la forma humana de comunicación y re-creación de sentido, a la que deberíamos aspirar. Y re-creación lo asumo aquí también como la creación y cambio de significación. Umberto Eco, lo denominaría quizá como la semiosis infinita. Bajtin señala que,

No existe ni la primera ni la última palabra, y no existen fronteras para un contexto dialógico (asciende a un pasado infinito y tiene a un futuro igualmente infinito). Incluso los sentidos pasados, es decir generados en el diálogo de los siglos anteriores, nunca pueden ser estables (concluidos de una vez para siempre, terminados); siempre van a cambiar renovándose en el proceso de desarrollo posterior del diálogo. En cualquier momento del desarrollo del diálogo existen masas enormes e ilimitadas de sentidos olvidados, pero en los momentos determinados del desarrollo ulterior del diálogo, en el proceso, se recordarán y revivirán en un contexto renovado y en un aspecto nuevo. No existe nada muerto de una manera absoluta: cada sentido tendrá su fiesta de resurrección. Problema del gran tiempo (1998: 392-393, cursivas mías).

En este punto, Bajtin señala algo fundamental de la dialogía como fundamento de la coeducación: la necesidad de distinguir y apreciar, en la interacción, la dialogía que se despliega con uno mismo y la que se desarrolla en-el-umbral con el otro, es decir, en el juego de espejos de la identidad con la alteridad, él señala que,

Las diferencias filosóficas y estéticas entre una autocontemplación interna (yo-para-mi) y la contemplación de su persona en el espejo (yo-para-otro), desde el punto de vista del otro. ¿Es posible contemplar y comprender su 
apariencia externa desde el punto de vista del yo-para-mi? (Bajtin, 1998: 394).

Lo que Bajtin está proponiendo es el punto de partida de todo proceso civilizatorio, es decir la construcción del semejante (en cristiano, el prójimo, si se quiere), que en coeducación supone el cuidado de cada uno, que es lo mismo que decir, el cuidado de el-otro-como-sí-mismo (Ricœur), en la relación.

\section{La cooperación y la coeducación}

Richard Sennett, en su libro Juntos, desarrolla este concepto (dialogía), en lo que denomina «el marco mental de la cooperación» y lo define como «un intercambio en el cual los participantes obtienen beneficios del encuentro" (Sennett, 2012: 18) ${ }^{15}$, y agrega que, inclusive "los animales sociales cooperan (...) para realizar lo que no pueden hacer solos» (Sennett, 2012: 18). Es importante seńalar que la cooperación no elimina la competencia, sino al contrario, pueden combinarse «como cuando los niños cooperan en el establecimiento de reglas básicas para un juego en el cual luego compiten entre sí» (Sennett, 2012: $18)^{16}$. Este proceso afecta tanto a las relaciones privadas, como a los mercados económicos, la política, la diplomacia, así como a los rituales.

Para este propósito plantea una cuestión que aparentemente es simple, pero que tiene una complejidad emosignificativa muy grande cuando se la tiene que aplicar: la capacidad de escucha.

Saber escuchar requiere otro conjunto de habilidades, las de prestar cuidadosa atención a lo que dicen los demás e interpretarlo antes de responder, apreciando el sentido de los gestos y los silencios tanto como el de los enunciados. Aunque para observar bien tengamos que contenernos, la conversación

15 Minka, ayni, en Perú; minga, en Colombia; tekio, en México, son formas sociales de cooperación.

${ }_{16}$ Inclusive, en el ayni y la mika, los participantes compiten tanto por hacer más rápido la tarea y por hacerlo mejor. 
que de ello resulte será un intercambio más rico, de naturaleza más cooperativa, más dialógica (Sennett, 2012: 30, cursivas mías).

Es interesante observar el uso de su biografía que hace el autor de El extranjero, quien hace alusión a su vida de músico para ilustrar las formas de interacción, donde enfatiza la diferencia entre practicar y ensayar: «la primera es una experiencia en solitario, la segunda es colectiva» dice, y luego agrega que el ensayo "convierte hábitos musicales en conciencia compartida", mientras que en la práctica, «el músico vuelve una y otra vez a su parte a fin de que los pasajes se conviertan en rutinas bien establecidas» (Sennett, 2012: 32).

Sennett opone la dialogía a la Dialéctica, y señala que ésta consiste en un juego verbal de los opuestos donde «debe construir poco a poco una síntesis; la dialéctica se inaugura con la observación de Aristóteles en Política según la cual "aunque usemos las mismas palabras, no podemos decir que hablamos de lo mismo"; el objetivo es llegar finalmente a una comprensión común. La habilidad en la práctica de la dialéctica consiste en detectar qué podría establecer ese fundamento común» (Sennett, 2012: 36, cursivas mías). «Algo parecido pasa en un ensayo musical cuando un ejecutante dice: "No capto lo que haces, ¿es esto?”. La formulación le hace a uno pensar otra vez en el sonido y es posible que el resultado sea un ajuste al mismo, pero no una copia de lo que se ha oído» (Sennett, 2012: 37).

Lo que Sennett está promoviendo es que: relativicemos las convicciones; acomodemos nuestros ritmos; esperemos oír/para saber; interpretar y, ya luego, responder.

Sennett indica que para Bajtin, la dialogía no designa una "discusión que se resuelva en el hallazgo de un fundamento común, sino que, aún cuando no se llegue "a compartir acuerdos, en el proceso de intercambio, los interlocutores pueden haber tomado mayor conciencia de sus propios puntos de vista y haber aumentado su comprensión mutua"» (Sennett, 2012: 37, cursivas mías). Han construido un cierto horizonte que quizá puedan compartir.

Sin embargo, la propuesta de Richard Sennett puede tener un traspiés: los invito, a cada uno de ustedes, a ponerle un nombre al interlocutor que propone el autor de Juntos: piensen en el vecino insoportable, en el compañero de trabajo o el jefe que les hace la vida imposible, en el hombre o mujer que los maltrata, 
y verán que la utopía se desinfla. Por otro lado, debemos ser conscientes de que ponerle nombre a la posible escucha es cambiar de escala: de lo público a lo privado, de lo colectivo a lo personal, de lo abstracto a lo concreto, e inclusive de lo teórico a lo circunscrito. Esto muestra la complejidad de la interpretación que se opone al facilismo del sinecdoquista empírico y del fundamentalista teórico (cuasi religioso). Por lo que el «traspiés» se supera sólo en otra escala, la pública.

\section{III.- Lenguaje, violencia y paz}

Considero que el lenguaje y el pensamiento se formatean mutuamente. En este sentido, desde hace ya un tiempo, he venido sosteniendo que una gran mayoría habita fragmentos de sentido inconexos, promovidos por políticas públicas y privadas que buscan dificultar el pensamiento relacional, complejo y crítico. La ciudad ya había fragmentado la vida del urbícola, como diría Simmel, pero hoy las nuevas tecnologías han acelerado el proceso. Mucha gente piensa y actúa metonímicamente, es decir caracteriza atendiendo sólo a un fragmento, como lo define un personaje de Fahrenheit 451:

No es posible construir una casa sin clavos ni maderas. Si no quieres que se construya una casa, esconde los clavos y la madera. Si no quieres que un hombre sea políticamente desgraciado, no lo preocupes mostrándole dos aspectos de una misma cuestión. Muéstrale uno. (Beatty, en Bradbury, 2013: 83-84).

Esto tiene consecuencias devastadoras en el pensamiento: lo simplifica, lo trivializa, lo sinecdoquiza. Es quizá por ello que una gran proporción de la población hoy habita fragmentos inconexos que dificultan un razonamiento básico, y alejan de la posibilidad de formulación de los problemas. En este proceso, una de las damnificadas más inmediatas es la memoria, instalando al ser en un presentismo (¿eufórico?) utilitarista y/o "placentero».

Para comprender el lenguaje, hay que abordar el que se produce en la interacción entre escuela, vida cotidiana y medios de comunicación, porque es en su intersección donde surge el ciudadano contemporáneo, con sus posibilidades y limitaciones. En este crucero se facturan la cultura de paz o la cultura de violencia. 
Quisiera iniciar este acápite señalando que el lenguaje instituye realidades, y tiene poder de conservación y de transformación de dichas realidades. Como punto de partida de esta exposición, me interesa enfatizar tanto el carácter permanente como cambiante del lenguaje, para luego mostrar su potencialidad para contribuir a la cultura de paz, para lo que debo incidir en la modulación de las acciones y emociones a través del lenguaje, otorgándoles sentido (emosignificación). Debo advertir también que el lenguaje puede permitir u obstruir el acceso a lo real, entendido éste como lo social, lo económico, lo político, lo material, lo funcional, entre otras. Parto también de lo señalado por George Steiner, que,

Todos los actos filosóficos, todo intento de pensar, con la posible excepción de la lógica formal (matemática) y simbólica, son irremediablemente lingüísticos. Son hechos realidad y tomados como rehenes por un movimiento u otro de discurso, de codificación en palabras y gramática (Steiner, 2012: 13).

\section{¿Es que todo está claro?}

Debo advertir que el lenguaje no aclara todo, porque no todo puede ser dicho. Sin embargo, no todo el mundo puede tener conciencia de lo que les habita "entre-líneas» ${ }^{17}$, y ello también, si bien abarca al silencio, se refiere más a la tracción-fricción entre lo dicho y lo no dicho; a aquella angustia de sentir que sedimentos o proyecciones queda «algo" sin decir, que no lo podemos decir. Es como referirse a la «cara oculta de la luna» que tiene el lenguaje, como puede expresarlo, desde otra perspectiva, el escritor colombiano, Héctor Abad Faciolince:

Yo recordaba que muchas veces mi papá me había dicho que todo ser humano, la personalidad de cada uno, es como un cubo puesto sobre una mesa. Hay una cara que podemos ver todos (la de encima); caras que pueden ver algunos y otros no, y si nos esforzamos podemos verlas también nosotros mismos (las de los lados), una cara que sólo vemos nosotros (la que está al frente de nuestros ojos); una cara que sólo ven los demás (la que está frente

17 «... El meollo, el mensaje filosófico, está en lo que no se dice, en lo que permanece tácito entre líneas» (Steiner, 2012: 14). 
a ellos); y una cara oculta a todo el mundo, a los demás y a nosotros mismos (la cara en la que el cubo está apoyado). Abrir el cajón de un muerto es como hundirnos en esa cara que sólo era visible para él y que sólo él quería ver, la cara que protegía de los otros: la de su intimidad (Abad, 2018: 265).

\section{Lenguaje, política y democracia}

En un graffiti se lee: «Democracia, misma mierda con diferentes moscas». Es una frase que muestra bien el sentimiento de frustración sobre las democracias realmente existentes, pues siendo en la escatológica figura -la democracia igual a mierda-, las moscas que se alternan son los miembros de la "clase política», que captura el poder con estilo y moral mafioso.

Es éste un déficit que la Democracia debe afrontar a través, entre otras cosas, de la coeducación. No abundaré en los significados históricos adjudicados a la construcción de la democracia, y sólo indicaré que su ejercicio es una constante construcción y depende, como un factor central, de la fuerza y la claridad de las ideas y los conceptos, que están también relacionados con la función de los ideales y valores que impulsan y concretizan en el discurso y en las prácticas individuales y colectivas. Si bien tiene que ver con un asunto de gobierno, tiene que ver también con lo cotidiano, y con la coeducación.

Jürgen Habermas definió la esfera pública como el escenario donde se debaten racionalmente los problemas de la sociedad. Sin embargo, planteamientos posteriores de la significación y la comunicación social han rebatido aquella supuesta racionalidad y han introducido el papel de las emociones que reconfiguran los sentidos y enmascaran los intereses que se pretenden promover.

Más recientemente, el pensador esloveno Slavoj Žižek, indica la decisiva influencia del poder en la instalación de la agenda pública y señala que «la lucha por la hegemonía ideológico-política es, por tanto, siempre una lucha por la apropiación de aquellos conceptos que son vividos "espontáneamente" como "apolíticos", porque trascienden los confines de la política» (2010: 15). En esta dirección introduce la "fuerza» como condición para el diálogo: 
En este sentido, "política» $\mathrm{y}$ "democracia» son sinónimos: el objetivo principal de la política antidemocrática es y siempre ha sido, por definición, la despolitización, es decir, la exigencia innegociable de que las cosas «vuelvan a la normalidad", que cada cual ocupe su lugar... La verdadera lucha política, como lo explica Rancière contrastando a Habermas, no consiste en una discusión racional entre intereses múltiples, sino que es la lucha paralela por conseguir hacer oír la propia voz y que sea reconocida como la voz de un interlocutor legítimo (Žižek, 2010: 26-27).

El poder instituido ignora a los más débiles, éstos tienen que obligarlo a dialogar, por ejemplo generando las «mesas de negociación». Distinguiendo la administración del poder de su disputa, dice que,

Estamos ante el foso que separa el verdadero acto político de la "gestión de las cuestiones sociales dentro del marco de las actuales relaciones sociopolíticas»: el verdadero acto político (la intervención) no es simplemente cualquier cosa que funcione en el contexto de las relaciones existentes, sino precisamente aquello que modifica el contexto que determina el funcionamiento de las cosas (Žižek, 2010: 34, cursivas mías).

Es decir, pensando en el mediano y largo tiempo, no sólo en lo urgente y lo inmediato. Una característica del pensamiento metonímico es la inmediatez. Permítaseme una digresión sobre la inmediatez y la vida contemporánea en la posmodernidad. La inmediatez es el tiempo que habitan la mayor parte de las personas; es su forma temporal de habitar los fragmentos holográficos como escenarios de significación sinecdóquica: de ese cronotopo pragmatista surgen los votos de Trump ${ }^{18}$, Bolsonaro y Keiko Fujimori... También surge una prensa sensacionalista que des-cuida el horizonte para responder y en un ambiente de pelea, responde de inmediato: ellos siempre están urgidos, el golpe se responde con otro golpe.

18 Joseph Stiglitz señala que «Trump es una personalidad conflictiva, y cuando se vaya deberíamos reflexionar cómo alguien tan perturbado y moralmente deficiente pudo llegar a ser elegido presidente del país más poderoso del mundo» (2019: 11). 
Aquí reentramos a lo que venía señalando insistentemente: el lenguaje marca la naturaleza de la relación social, al mismo tiempo que es expresión de ésta. Analizar el lenguaje, no sólo permite acceder mejor a lo social y político, sino reconstruye nuestra relación con dichos contextos. Examinemos una de sus expresiones: la prensa sensacionalista.

\section{Los lenguajes de la prensa amarillista}

Tal vez, en nuestra breve historia evolutiva, aún no hayamos aprendido a pensar. Puede que la etiqueta homo sapiens, excepto para unos cuantos, sea una jactancia infundada” (George Steiner).

(Lunfardo, es un) «vocabulario gremial (...) tecnología de la furca y de la ganzúa», «lengua especializada en la infamia y sin palabras de intención general» (Jorge Luis Borges).

$\mathrm{Al}$ analizar las condiciones de agresividad contemporánea, Richard Sennett dice que la expresión "“Jódete, jódete!”, que aparece en la canción Fuck you very much, de Lily Allen, es más que una explosión; es paralizante. Ante esta explosión, la respuesta más probable será “jódete tú también!” A partir de ese momento, los antagonistas quedan encerrados en sí mismos» (Sennett, 2012: 41$)^{19}$, dispuestos a enfrentarse a la «menor provocación», que es un núcleo de interacción comunicativa fundamental ${ }^{20}$ de la prensa amarillista que analizamos brevemente.

19 Ver las llamadas cadenas esquismogenéticas (Bateson, en Bauman, 2001: 34).

$20 \mathrm{Al}$ observar los rostros y los gestos de los políticos (y de sus seguidores), vemos que llevan consigo siempre una gran dosis de agresividad. Hace falta un análisis del lenguaje gestual y para-verbal de la "clase política". 


\section{EI estilo y el contenido}

Considero que el estilo de la enunciación condiciona el pensamiento y a la inversa, reforzándose mutuamente en la facturación del ser, como lo señala Edna O’Brien, «el lenguaje de las personas es un índice de su integridad y de su inteligencia. Y si los políticos eligen un lenguaje barato, iracundo y agresivo, los seguidores hacen lo mismo. Quien abarata el lenguaje, abarata el pensamiento» (2016: 54). Pero, también puede constarse que ocurre «al revés» ${ }^{21}$, que ese lenguaje del político, se adapta al de aquellos a los que se dirige, en un continuum permanente. Como una constatación básica inicial, debo decir que la prensa sensacionalista centra su eje discursivo en la pelea, no en el conflicto.

$\mathrm{Al}$ respecto de la interacción formativa entre estilo del lenguaje y pensamiento, George Steiner, advierte sobre la relación entre la forma y el contenido:

Algo que se ha aclarado menos es la incesante y determinante presión de las formas del habla, del estilo, sobre los sistemas filosóficos y metafísicos. ¿En qué aspectos una propuesta filosófica, aún en la desnudez de la lógica de Frege, es retórica? ¿Puede algún sistema cognitivo y epistemológico ser disociado de sus convenciones estilísticas, de los géneros de expresión prevalecientes o puestos en entredicho en su época y entorno? (2012: 15)

\section{Las emociones y el lenguaje}

El sensacionalismo busca activar las emociones del lector-oyente y es el mecanismo o dispositivo que, aparentando proporcionar «información entretenida», cambia el estatus de un hecho irrelevante, el que es transformado, vía titular privilegiado, en noticia supuestamente importante. Es el sinecdoquismo como dispositivo de significación. El tratamiento es casi siempre provocador: busca enervar tanto a quien es objeto de su escarnio, como al auditorio, a quien intenta poner en contra, aunque probablemente éste, ya está parcializado ${ }^{22}$.

21 Entrecomillo «al revés» porque no sólo es un flujo que la adaptación posibilita, sino viene instituyéndose en el escenario mayoritario de la producción de la insignificancia (Castoriadis) y éste es, para un importante sector de la población, la única forma de producción de significaciones.

22 Por una concatenación de actos semejantes que ayudan a construir y reforzar estereotipos y estigmas. 
En este sentido, me gustaría relatar lo que el semiólogo italiano Umberto Eco, denomina la "máquina del fango", que es una suerte de modus operandi tendiente a la deslegitimación del adversario. El autor de La estructura ausente, seńala que no es necesario decir que alguien "ha matado a su abuela», sino que puede decirse algo muy normal. Pone el ejemplo del juez que dictó una sentencia contraria a ciertos intereses, y que fue fotografiado sentado en una banca de un parque, fumando cigarrillos, mientras la prensa subrayaba sus calcetines color granate, con lo que se intenta proyectar una sombra de extrañeza sobre él sin decir nada. Relata también su propia experiencia, cuando fue fotografiado comiendo con palillos en un restaurante chino, con «un desconocido». El autor de Número cero, resalta que ese desconocido, lo es para quien le tomó la fotografía, pero para él es su amigo, y el restaurante es uno al que va siempre, aunque esto no lo conozcan las audiencias (y los operadores de la máquina cuentan con este desconocimiento para hacerse eficaces en su deslegitimación al instalar la sospecha) y concluye que «el auténtico juego es esta pasividad de los consumidores de noticias».

Así vemos que hay un contexto más amplio que va delineando formas que se imponen a la mayoría, especialmente desde los medios. Ellos no sólo ponen los temas de la agenda pública, sino también las formas de tratarlos. La prensa amarillista, en este sentido, estimula y crea al lector-que-sospech ${ }^{23}$, y lo que es peor, induce la ruta de la sospecha.

\section{EI lenguaje de las redes sociales}

Las redes sociales emergieron como una alternativa frente al autoritarismo y la parcialidad de los medios de comunicación; sin embargo, en la actualidad son el escenario que reproduce lo que en los medios tradicionales se promueve: el odio y el deseo de aniquilación del otro, del adversario, que rápidamente se convierte en enemigo. Así, según Sara Bakewell, «el siglo XXI está lleno de gente egocéntrica (...) un rastreo de media hora a través de los océanos ciberespaciales de blogs, twitters (...) nos ofrece millares de individuos fascinados por su propia personalidad y que reclaman atención a gritos» (cit. en Sennett, 2012: 446-447). Sennett señala que si bien es correcta la observación, es incompleta, y da el

23 Semejante al que Jorge Luis Borges anunciaba al referirse al cuento policial, «un lector que lee con incredulidad, con suspicacia, una suspicacia especial» (Borges, 1999: 64). 
ejemplo de los pacientes de cáncer, quienes complementan y a veces superan lo que ocurre en sus intercambios con sus médicos respectivos.

Sennett señala que lo más preocupante es el efecto de deterioro de la «blogosfera política, llena como está de agresivos embates de opinión antes que de una auténtica discusión de concesiones mutuas, formando un gigantesco archipiélago, como teme Cass Sunstein, de expresiones del tipo "nosotros-contra-ellos" " (Sennett, 2012: 47, cursivas mías). Esto nos confronta a la tarea de trabajar el sentido de las relaciones sociales, para lo que es fundamental la coeducación que promueva el respeto.

Frente a este panorama polarizador, el lenguaje podría utilizarse para atenuar e introducir dispositivos de convivialidad. Uno de esos es el subjuntivo.

\section{El subjuntivo versus el autoritarismo dogmático}

Richard Sennett, cuenta que, en sus ensayos con jóvenes músicos ingleses, usaban expresiones como: "posiblemente», "tal vez», "yo hubiera pensado...», y enfatiza que de esa manera, "los ensayos eran más eficaces porque ese modo subjuntivo abría un espacio para el experimento; la provisionalidad implica una invitación a los otros a unirse al intento. No cabe duda de que la inseguridad, al igual que la turbación, puede ser la forma inversa del narcisismo, pues el sujeto está dominado por una conciencia excesivamente intensa de sí mismo.» (Sennett, 2012: 42, cursivas mías).

En este contexto, Sennett establece una articulación interesante entre empatía, simpatía, conversación y etnografia:

En un ensayo musical, un ejecutante de un instrumento de cuerda puede advertir que sus compañeros de conjunto oyen una frase musical de una manera totalmente diferente y, por tanto, la frasean de otro modo con sus arcos; el ejecutante registra la diferencia. La respuesta simpática consistiría en identificarse con ellos e imitarlos. La respuesta empática es más fría: "tú subes el arco, yo lo bajo..."; puede que la diferencia se mantenga, pero se ha puesto en marcha una señal de reconocimiento de lo que uno ha estado haciendo. En una entrevista, la empatía del que escucha puede expresarse mediante el mantenimiento del contacto visual aunque se guarde silencio, con lo que se 
transmite más el mensaje de "Te estoy prestando atención" que el de "Sé lo que sientes". La curiosidad tiene un papel más importante en la empatía que en la simpatía» (Sennett, 2012: 40, cursivas y negritas mías).

Sennett recalca la diferencia entre ambas formas de interrelación porque en su matiz se ubica la forma de interacción que posibilita el intercambio con los otros, puesto que, a pesar de que ambas significan reconocimiento y crean un vínculo, "una es un abrazo, mientras que la otra es un encuentro». La simpatía, a través de actos imaginativos, produce identificación; mientras que la empatía "presta atención a otra persona en su particularidad». Así, recalca que «se ha pensado que la simpatía es un sentimiento más fuerte que la empatía, porque "Siento vuestro dolor" pone el acento en lo que siento, activa el ego propio. La empatía es un ejercicio más exigente, al menos en la escucha; el que escucha tiene que salir fuera de sí mismo» (Sennett, 2012: 40, cursivas mías).

Así, el subjuntivo ayuda a contener la asertividad, que conduce al menosprecio del saber y la experiencia de los otros y ayuda a abrir «un espacio gracias al cual nosotros podemos examinar la vida interior de otra persona y ésta a su vez examinar la nuestra» (Sennett, 2012: 43). Es decir, iniciar o continuar el diálogo.

En este contexto, la memoria asume el papel de marco o fondo que provee los recursos de la introspección proyectiva, porque se la obliga a pensar el presente de la interacción bajo sus claroscuros y, en este punto, aparece su papel fundamental en la definición de lo propio y lo ajeno, no como un ejercicio de exclusión, sino de auto exilio fugaz como camino al entendimiento del otro espejeando consigo mismo. 


\section{Bibliografía}

Abad Faciolince, Héctor (2018). El olvido que seremos, Bogotá: Alfaguara.

Academia Universal de las Culturas (2002). ¿Por qué recordar?, Barcelona: Granica Ediciones.

Appadurai, Arjum (2007). El rechazo de las minorias. Ensayo sobre la geografía de la furia, Barcelona: Tusquets Editores.

Bajtin, Mijail (1998 [1979]). Estética de la creación verbal, México: Siglo XXI.

Bauman, Zygmunt (2001). La globalización. Consecuencias humanas, México: Fondo de Cultura Económica.

Bauman, Zygmunt (2006). Modernidad líquida, Buenos Aires: Fondo de Cultura Económica.

Bauman, Zygmunt (2007). Miedo líquido. La sociedad contemporánea y sus temores, Barcelona: Paidós.

Benjamin, Walter (2010). «Para una crítica de la violencia», Ensayos escogidos, Buenos Aires: El cuenco de plata, pp. 153-180.

Bradbury, Ray (2013). Fahrenheit 451, México: SNT de Infonavit.

Candau, Joël (2002). Antropología de la memoria, Buenos Aires: Nueva Visión.

Castoriadis, Cornelius (1983). La institución imaginaria de la sociedad. Vol. 1, Barcelona: Tusquets Editores.

Castoriadis, Cornelius (1987). La institución imaginaria de la sociedad. Vol. 2, Barcelona: Tusquets Editores.

Castoriadis, Cornelius (2002 [1999]). «Las raíces psíquicas y sociales del odio», en Figuras de lo pensable (Las encrucijadas del laberinto IV), México: Fondo de Cultura Económica, pp. 183-196.

Castoriadis, Cornelius (2002). La insignificancia y la imaginación. Diálogos, Madrid: Trotta.

Comisión de Derechos Humanos (2012). Los muertos de Ayacucho y sitios de entierro clandestinos, Lima: COMISEDH.

Coronel Aguirre, José (1996). «Violencia política y respuestas campesinas en Huanta», en Carlos Iván Degregori (ed.). Las rondas campesinas y la derrota de Sendero Luminoso, Lima: Instituto de Estudios Peruanos, pp. 29-116.

Comisión de Entrega de la CVR (2004). Hatun Willakuy. Versión abreviada del Informe Final de la Comisión de la Verdad y Reconciliación, Lima: CVR. 
Degregori, Carlos Iván (1995). «El estudio del otro: cambios en el análisis sobre etnicidad», en Julio Cotler (ed.). Perú, economía, sociedad y politica 1964-1994, Lima: Instituto de Estudios Peruanos, pp. 303-332.

Dubet, François (2006). El declive de las instituciones. Profesiones, sujetos e individuos en la modernidad, Barcelona: Gedisa.

Duschatzky, Silvia y Corea, Cristina (2005). Chicos en banda. Los caminos de la subjetividad en el declive de las instituciones, Buenos Aires: Paidós.

GADAMER, Hans-Georg (1991). La actualidad de lo bello. El arte como juego, simbolo y fiesta, Barcelona: Paidós.

Gadamer, Hans-Georg (1988). Verdad y método, Salamanca: Sígueme.

García Alonso, María (2017). «Purificación de la memoria en la España del Siglo XXI: transformaciones y confrontaciones», en Beatriz Nates Cruz (coord.). Memoria y territorio, Bogotá: Instituto Colombiano de Antropología e Historia, pp. 15-27.

García Canclini, Néstor (1995). Consumidores y ciudadanos. Conflictos culturales de la globalización, México D.F.: Editorial Grijalbo.

GonzÁlez-VAlerio, María Antonia (2004). «Historicidad y temporalidad en la hermenéutica de Gadamer», en González-Valerio, Herrerías, Illescas y Luna. Tres miradas en torno al tiempo: Merleau-Ponty, Gadamer y Ricour, México: UAM-CONACYT, pp. 109-134.

Halbwachs, Maurice (2004). Los marcos sociales de la memoria, Barcelona: Anthropos.

Huxley, Aldous (2014). Un mundo feliz, México: SNT Infonavit.

Kandel, Eric (2012). En busca de la memoria. El nacimiento de una nueva ciencia de la mente, Madrid: Katz Editores.

Kurnitzky, Horst (2002). Civilización incivilizada. El imperio de la violencia en el mundo globalizado, México: Océano.

Lechner, Norbert (1995). Los patios interiores de la democracia. Subjetividad y Politica, Santiago: Fondo de Cultura Económica.

Lotman, Iuri (1993 [1987]). «El símbolo en el sistema de la cultura», en Escritos N $^{\circ} 9$, Puebla: Centro de Estudios del Lenguaje, BUAP, pp. 47-60.

Melucci, Alberto (2001). Vivencia y convivencia, Madrid: Editorial Trotta.

Melucci, Alberto (2010). Acción colectiva, vida cotidiana y democracia, México: Colegio de México.

Milmaniene, José E. (2005). El tiempo del sujeto, Buenos Aires: Editorial Biblos.

Oz, Amos. «La cuenta no está cerrada», http://www.youtube.com/watch?v-rwrW71Q$3 \mathrm{Z} 8 \mathrm{U}$

ÉNDOXA: Series Filosóficas, n. 44, 2019, pp. 185 - 216. UNED, Madrid 
Ricceur, Paul (2002). «Definición de la memoria desde un punto de vista filosófico», en Academia Universal de las Culturas, ¿Por qué recordar?, Barcelona: Granica Ediciones, pp. 24-28.

Roxin, Claus (2000). Autoria y dominio del hecho en Derecho Penal, Barcelona: Marcial Pons.

Sennett, Richard (2012). Juntos. Rituales, placeres y politica de cooperación, Anagrama, Barcelona.

Simmel, Georg (2010). El conflicto. Sociología del antagonismo, Madrid, Sequitur.

Steiner, George (2012). La poesía del pensamiento. Del helenismo a Celan, México: Fondo de Cultura Económica.

Vergara Figueroa, Abilio (2005). "Ensayo introductorio», en Edilberto Jiménez Quispe, Chungui. Violencia y trazos de memoria, Lima: IEP, COMISEDH, $2^{\text {da }}$. Edición, pp. 36-67.

Vergara Figueroa, Abilio (2006). «Videoescándalos, imaginarios de la sombra: rituales y lenguaje de una comunidad mafiosa", en El resplandor de la sombra. Imaginación politica, producción simbólica, humor y vidas macropolitanas, México: Ediciones Navarra, pp. 61-108.

Vergara Figueroa, Abilio (2018). «Territorialidades bajo presión violenta», en Diana Carolina Rico y Julián López, Territorio, conflictos y posconflictos. Mirada interdisciplinar, Barranquilla: Universidad del Norte, pp. 11-48.

Žı̌̌EK, Slavoj (2010). En defensa de la intolerancia, España: Diario Público.

ŽıžEK, Slavoj (2006). Visión de paralaje, México: Fondo de Cultura Económica.

Recibido: 16/09/2019

Aceptado: 10/12/2019

Este trabajo se encuentra bajo una licencia de Creative Commons Reconocimiento-No Comercial-SinObraDerivada 4.0 